\title{
O Método Arqueológico de Foucault: Uma perspectiva do Design da Informação
}

\section{Foucault's Archaeological Method: An Information Design perspective}

\author{
Mauricio Perin, Bolívar Escobar, Marcos Beccari
}

Arqueologia do Saber, Foucault, Design da Informação, Método, Discurso, História

\begin{abstract}
Este artigo apresenta e discute o processo metodológico utilizado por Foucault em A Arqueologia do Saber (1969) e as possibilidades que ele oferece ao Design da Informação. De início, contextualiza-se a relação do pensamento pós-estruturalista - que inclui as contribuições de Foucault na virada dos anos 1960-70 - com a prática do design gráfico, a partir do exemplo da Cranbrook Academy of Design. Em seguida, discutem-se os espaços de sobreposição entre os dois temas que não foram cobertos pela experiência da escola norte-americana. A partir daí realiza-se uma descrição do Método Arqueológico e dos principais conceitos utilizados por Foucault nessa proposta. Por fim, demonstra-se a aplicação do processo na pesquisa em Design da Informação, por meio da discussão do modo de olhar para artefatos "monumentalizados" pela disciplina. Como considerações finais, são discutidas transposição do objeto inicial do método arqueológico (história das ciências naturais e humanas) para pesquisas teóricohistóricas no Design da Informação.
\end{abstract}

Archaeology of Knowledge, Foucault, Information Design, Method, Discourse, History

This paper presents and discusses the method introduced by Foucault in The Archeology of Knowledge (1969) and the possibilities it offers to the field of Information Design. At the outset, the relation of poststructuralist thought - which includes Foucault's contributions at the turn of the 1960s - is contextualized, based on the example of the Cranbrook Academy of Design. Next, the overlapping spaces between the two themes, that were not covered by that North American school experience, are discussed. From there a description of the Archaeological Method and of the main concepts used by Foucault in this activity is realized, by means of looking at design artifacts "monumentalized" by Information Design as a discipline. Finally, the possibilities of application of this method in Design research are discussed, considering the transposition from its original environment in the history of natural and human sciences.

\section{Introdução}

Quando o pensamento pós-estruturalista - de autores como Michel Foucault, Roland Barthes e Jacques Derrida - é introduzido por Katherine McCoy no departamento de design gráfico da Cranbrook Academy of Design, a partir dos anos 1970, inaugura-se uma das mais conhecidas aproximações entre uma corrente filosófica e a atividade do design (Lupton \& Miller, 2011). Partindo de conceitos como desconstrução e múltipla significação - e discutindo, entre outros tópicos, as relações entre designers e seu conteúdo autoral -, a produção da escola explora

Anais do $10^{\circ} \mathrm{CIDI}$ e $10^{\circ} \mathrm{CONGIC}$

Kelli C.A.S. Smythe, Rafael de Castro Andrade (orgs.)

Sociedade Brasileira de Design da Informação - SBDI

Curitiba | Brasil | 2021
Proceedings of the $10^{\text {th }} \mathrm{CIDI}$ and $10^{\text {th }}$ CONGIC

Kelli C.A.S. Smythe, Rafael de Castro Andrade (orgs.)

Sociedade Brasileira de Design da Informação - SBDI Curitiba | Brazil | 2021 
fronteiras, questiona convenções e subverte expectativas inerentes à atividade do design (Bomeny, 2009). Com isso, a Cranbrook conquista um lugar singular entre as instituições de ensino do design do mundo (Lupton \& Miller, 2011). Posição essa que, não se limitando ao campo do ensino, influencia também a prática profissional do design - de maneira que Rick Poynor compara (em entrevista presente em Camargo, 2011) ao que fazem a Bauhaus e a Escola de Ulm em décadas anteriores.

No entanto, tal aproximação com a filosofia francesa contemporânea toma forma mais como uma inspiração, ou "postura", em relação ao design, do que como uma base de pesquisa ou metodologia de estudo (Lupton \& Miller, 2011). Independente da relação original da Cranbrook com Barthes, Derrida, Foucault e outros pensadores, as suas experiências com a desconstrução e a crítica deixam como sua herança mais significativa para o design não a relação íntima com a teoria pós-estruturalista, mas um estilo visual "pós-moderno" ou "desconstrutivista". Um "ismo" que encontra seu lugar no vocabulário do design gráfico em sua forma mais superficial, como mero clichê visual (Lupton \& Miller, 2011).

$\mathrm{E}$, se a relação dessas teorias com a prática do design revela-se rasa, a infusão direta do pós-estruturalismo no estudo do design - como no contexto das experimentações de McCoy e seus estudantes - corre o risco de tornar-se o que Beccari et. al. (2017) descreve como uma aplicação simplista do conhecimento filosófico no design: não só pelo seu "aspecto unilateral, isto é, com fim estrito de aprimorar o design [mas devido à própria] ideia segundo a qual os designers poderiam se servir da filosofia para refletir sobre aquilo que fazem" (p. 14). Sendo que tal problema não reside "no ato reflexivo em si, mas na ideia de que o pensamento reflexivo seja somente possível por meio da filosofia" (p. 15).

No âmbito do Design da Informação, podemos identificar essa mesma tendência em certa "disputa" pela identificação de um conhecimento filosófico em seus entrelaçamentos com a disciplina do design. Pettersson (2014) comenta como o Information Design Journal, quando lançado em 1979, carregava como proposta "ser um contraponto às identidades corporativas e gráficos chamativos que pareciam estar dominando o design dos anos 1980" (p. 3, tradução nossa). De fato, as bases epistemológicas do Design da Informação podem ser encontradas tanto na universalidade proposta por Tufte (1990), na busca pela facilidade de compreensão defendida por Schriver (1997), bem como na disciplina da Linguagem Gráfica, cuja atenção volta-se para questões de clareza e eficácia comunicacional (Pettersson, 2010). Quando Mijksenaar - evocando princípios do design moderno empregados por projetistas como Lloyd Wright e Gropius - busca identificar o sistema de pensamento que poderia embasar o Design da Informação, conclui que princípios de confiabilidade, utilidade e satisfação deveriam ser as prioridades dos artefatos informacionais (Mijksenaar, 1997). De tal forma que, enquanto a Cranbrook fundamentou-se no pós-estruturalismo, poderíamos afirmar que o Design da Informação aproxima-se da linha estruturalista e formalista de pensamento (Chromiec, 2020; Foucault, 2005).

Mediante esse contexto, nosso objetivo com o presente artigo é demonstrar como a visão pós-estruturalista - mais especificamente aquela encontrada no método arqueológico de 
Michel Foucault - poderia contribuir para a transversalidade epistemológica que constitui o campo do Design da Informação. Não propomos aqui, no entanto, defender uma "postura" pósestruturalista para novas teorias do Design da Informação. Nem, por outro lado, aplicar diretamente a metodologia e as estratégias oriundas dessa corrente filosófica em uma reflexão sobre a área. A partir da proposta de realizar "cortes transversais entre o design, a filosofia e outros campos de expressão criativa" (Beccari et. al., 2017, p. 16), pretendemos evidenciar, sob um prisma foucaultiano, a forma como determinados objetos são identificados como materializações do Design da Informação. Um processo que resulta da seleção de características comuns a tais artefatos, e se sustenta em pressupostos entendidos como válidos no campo do Design da Informação. Ainda que se sobressaiam em diferentes áreas de expressão, agrupamos aqui tais objetos com o objetivo de evidenciar como eles fazem surgir, a partir do campo do Design da Informação, um "pensamento complexo, múltiplo" (p. 17).

Por mais que Michel Foucault não descreva formalmente sua metodologia, o que hoje entende-se como "método arqueológico" tem suas bases no livro "A Arqueologia do Saber", publicado originalmente em 1969. Nosso tema central neste trabalho resume-se na pergunta que permeia toda obra do autor: "como foi possível o que é?" (Castro, 2015, p. 3). Tal questionamento não implica, porém, uma razão maior a ser desvelada como origem verdadeira dos acontecimentos: "as coisas poderiam ter sido de outro modo e também podem ser de outro modo" (Castro, 2015, p. 3). Pelo contrário, para a abordagem arqueológica:

O solo sobre o qual repousa é o que ela descobriu. As pesquisas sobre a loucura e o aparecimento de uma psicologia, sobre a doença e o nascimento de uma medicina clínica, sobre as ciências da vida, da linguagem e da economia [temas de trabalhos anteriores do autor], foram tentativas de certa forma cegas: mas elas se esclareciam sucessivamente, não somente porque precisavam, pouco a pouco, seu método, mas porque descobriram - neste debate sobre o humanismo e antropologia - o ponto de sua possibilidade histórica (Foucault, 2008, p. 18).

Apesar de seus temas diversos - e de suas especificidades que, a princípio, parecem thes dispersar para longe do domínio do Design da Informação -, tais textos se conectam por apresentarem uma abordagem nova e investigativa da história dos saberes. Uma perspectiva que, ao questionar os métodos, limites e temas próprios de uma história "convencional", não se prende a uma narrativa contínua de memória e melhoramento humano: deliberadamente, rejeita uma verdade definitiva sobre os fatos ou uma totalização da história (Foucault, 2008). Outrossim, "a arqueologia não pretende, nem considera possível, um estudo histórico capaz de esgotar todas as questões, todos os eventos, todos os discursos existentes na realidade pretérita" (Baptista, 2016, p. 277).

Martins et al. (2015) propõem novas metodologias para a pesquisa histórica do design gráfico. Os autores sugerem que a Efemerologia de Twyman e os resgates históricos salientados por Farias são maneiras de trazer para o campo do design os objetos que outrora seriam ignorados por propostas mais restritivas. Desde o seu esboço tentativo na composição de uma história alternativa da loucura, passando por sua consolidação no estudo do trajeto tortuoso das ciências humanas e, (fora das mãos de Foucault) em sua introdução nos mais variados campos contemporâneos (e.g. administração, comunicação, saúde pública, 
teledramaturgia e na própria disciplina da história ${ }^{1}$ ) -, o método arqueológico não cessa de oferecer as bases para um ângulo revelador de se olhar para o conhecimento. Agora, o apresentamos como um convite para ampliar o campo do Design da Informação em seus objetivos historiográficos.

\section{Método Arqueológico}

\section{Contextualização quanto aos objetivos}

Em sua proposta metodológica, Foucault se fundamenta não nas concepções históricoantropológicas previamente estabelecidas sobre a jornada da humanidade, que remontaria a uma verdade original cuja regência direciona esse percurso rumo a um melhoramento intrínseco; também não recorre aos rótulos e conceitos de uma história previamente mapeada que buscaria encaixar todo novo fato em uma narrativa universal convencionada anteriormente (Foucault, 2008). Ao contrário, Foucault se volta para recortes específicos que the permitem descrever - num dado contexto específico, e a partir das informações que desse contexto mesmo emanam - de que forma determinados discursos se formam e tornam possível aquilo que é hoje conhecido.

De tal maneira que é possível dizer que o método arqueológico não busca, como faria a história tradicional, transformar seu objeto de estudo - aqueles vestígios com os quais o pesquisador se depara, na forma de fragmentos dispersos de monumentos de um passado remoto - em documentos e "provas" de uma memória coletiva, que teriam a capacidade de contar a própria história. Tarefa essa que se tornaria especialmente infrutífera no âmbito do design, onde, ainda mais do que na ortodoxia historiográfica, os registros estudados não passam de "rastros que, por si mesmos, raramente são verbais, ou que dizem em silêncio coisa diversa do que dizem" (Foucault, 2008, p. 8) ${ }^{2}$.

Pelo contrário, aquilo que se busca na arqueologia é a utilização desse conjunto de registros materiais ${ }^{3}$ - que, de forma organizada ou espontânea, foram preservados e comunicados dentro de determinado contexto social até chegarem às mãos de quem os pesquisa - como ponto de partida para a compreensão de uma história que os elabora e os carrega de status. Trata-se, portanto, de um trabalho "que transforma os documentos em monumentos e que desdobra [...] uma massa de elementos que devem ser isolados, agrupados, tornados pertinentes, inter-relacionados, organizados em conjuntos" (Foucault,

\footnotetext{
${ }^{1}$ Respectivamente: Costa, Guerra e Leão (2013); Baptista (2016); Pires e Botazzo (2015); Santos Neves e Carvalho (2014) e Gomes (2018).

${ }^{2}$ Em momento algum Foucault descreveu as particularidades de seu método com relação à atividade do design. O exemplo dado se refere, no texto original, justamente aos documentos com que a própria historiografia costuma trabalhar. A consideração, no entanto, de que o desafio da não verbalidade não só se faz presente, como é agravado pelos objetos de estudo do design, nos parece suficientemente pertinente.

${ }^{3}$ Registros que no âmbito do design podem ser entendidos como livros, textos, objetos, peças gráficas e de audiovisual, fotografias, desenhos, espaços etc.
} 
2008, p. 8). Finalmente, a fim de esclarecer o significado dado ao termo "arqueologia", e sua escolha como contraponto de uma história tradicional, o autor relata:

Havia um tempo era que a arqueologia, como disciplina dos monumentos mudos, dos rastros inertes, dos objetos sem contexto e das coisas deixadas pelo passado, se voltava para a história e só tomava sentido pelo restabelecimento de um discurso histórico; poderíamos dizer, jogando um pouco com as palavras, que a história, em nossos dias, se volta para a arqueologia - para a descrição intrínseca do monumento (Foucault, 2008, p. 8).

Traçamos um paralelo com o Design da Informação a partir de alguns dos principais exemplos acadêmicos recorrentemente elencados com base em sua notável relação entre informação e sua representação visual apontada por autores amplamente citados como Twyman (1982). Essa relação é encontrada nos icônicos gráficos de Florence Nightingale (séc. XIX), ou o mapa do metrô de Londres elaborado por Harry Beck em 1931, ou ainda, em mais um frequente destaque, nos balanços econômicos de William Playfair, dispostos em visualizações gráficas cartesianas no seu Atlas Comercial de 1786 (figura 1). Artefatos que, em suas constantes exposições, reforçam uma "monumentalização" no corpo discursivo próprio da disciplina.

Figura 1: Da esquerda para a direita: gráficos da variação da taxa de juros na Inglaterra, por Playfair (1786), os diagramas de mortalidade em hospitais de Nightingale (1858) e a primeira versão do mapa do metrô de Londres de Beck (1931). (Fonte: Wikimedia Commons e London Transport Museum@)

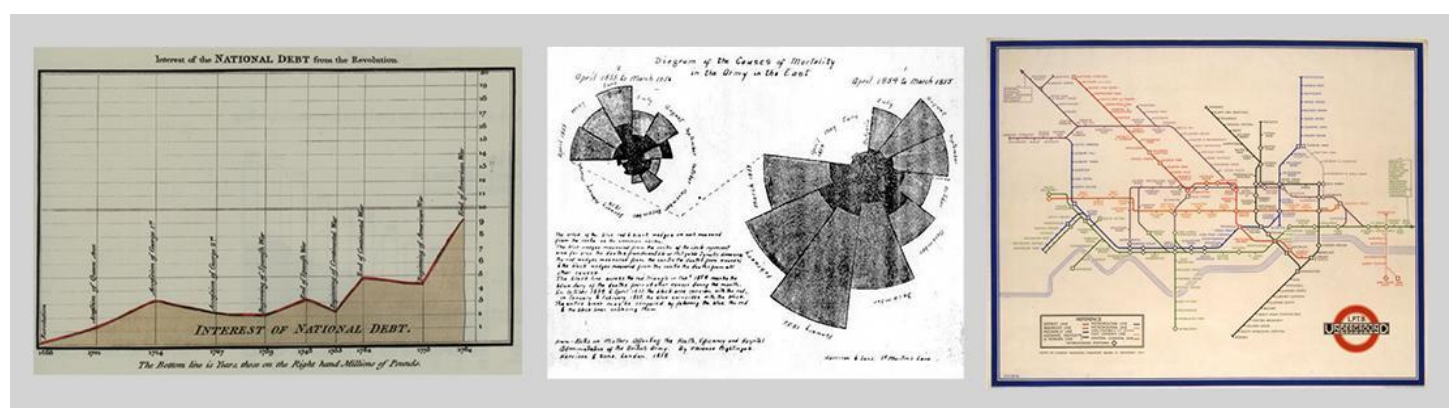

O que esperamos evidenciar aqui é a transversalidade desse tipo de artefato - e.g. um diagrama com propósitos de comunicação sanitária versus uma visualização abstrata de trajetos dos carros do transporte público. Nesses exemplos pontuais, a arqueologia aponta para um Design da Informação que surge no olhar que o identifica como tal, já que no contexto histórico de materialização essa nomenclatura ainda não existia. De tal forma que o "resgate" desses e de outros materiais sugeriria como ocorreu a formação do campo que entendemos, hoje, por Design da Informação.

\section{A abordagem analítica quanto aos objetos}

Tendo contextualizado o método arqueológico com relação aos seus objetivos, é tempo de esclarecermos também a forma particular com que ele encara seus objetos de estudo e a maneira prática com que os elabora. A primeira pode ser sintetizada como uma busca por limiares ao longo da história dos discursos que enredam o objeto de estudo, de tal forma que 
seja possível distinguir estratos desta história uns dos outros e, a partir deles, estabelecer séries definidas cada qual por critérios de periodização (Foucault, 2008).

Destarte, mais do que se preocupar com reconstruir uma verdade original a partir dos documentos analisados (confirmando determinada narrativa), a arqueologia se volta para o corpo documental com vistas a organizá-lo. Ela "recorta, distribui, ordena e reparte em níveis, estabelece séries, distingue o que é pertinente do que não é, identifica elementos, define unidades, descreve relações" (Foucault, 2008, p. 7). Da mesma forma, a preocupação não é com a consolidação de uma história global, uma que abarque simultaneamente a totalidade dos temas e permita enredar homogeneamente todo tipo de acontecimento, mas sim com a composição de histórias singulares.

Neste trabalho de organização, Foucault primeiramente sugere que se abandonem certas unidades e formas de classificar objetos, usualmente aplicadas na análise de documentos. $\mathrm{O}$ livro e a obra de um dado autor figuram entre tantos outros elementos que se deve deixar em suspenso na realização de uma análise arqueológica:

É que as margens de um livro jamais são nítidas nem rigorosamente determinadas: além do título, das primeiras linhas e do ponto final, além de uma configuração interna e da forma que Ihe dá autonomia, ele está preso em um sistema de remissões a outros livros, outros textos, outras frases: nó em uma rede (Foucault, 2008, p. 26).

Indo além da materialidade física do objeto livro, Foucault questiona sua pretensa unidade, que "não se indica a si mesma, só se constrói a partir de um campo complexo de discursos" (Foucault, 2008, p. 26). Com relação à unidade da obra, o autor começa por problematizar a atribuição de autoria, os pseudônimos e as diferentes relações que determinado autor poderia ter com cada documento:

O nome de um autor denota da mesma maneira um texto que ele próprio publicou com seu nome, um texto que apresentou sob pseudônimo, um outro que será descoberto após sua morte, em rascunho, um outro ainda que não passa de anotações, uma caderneta de notas, um "papel"? (Foucault, 2008, p. 26).

Foucault argumenta que aquilo que dá unidade à determinada obra não é uma qualidade intrínseca, ou um conjunto objetivo de regras, mas sim uma operação consciente e interpretativa que é desenvolvida individualmente para cada caso, de tal forma que quando se fala da obra de Nietzsche, por exemplo, não se está falando da mesma organização que compõe a obra de Mallarmé ou de qualquer outro autor. "A obra não pode ser considerada como unidade imediata, nem como unidade certa, nem como unidade homogênea" (Foucault, 2008, p. 27).

Além dos dilemas de autor e obra, Foucault descarta também a concepção de que todo discurso remontaria a uma versão anterior, ao que já foi dito anteriormente ou a um conceito amorfo que permeia o silêncio por trás dos discursos. Não deve haver, portanto, uma necessidade de justificativa para a origem de todo discurso, uma infinita cadeia de sucessões que, através de sua continuidade, invariavelmente resultaria em uma única origem verdadeira para tudo que é dito. 
É preciso estar pronto para acolher cada momento do discurso em sua irrupção de acontecimentos, nessa pontualidade em que aparece e nessa dispersão temporal que the permite ser repetido, sabido, esquecido, transformado, apagado até nos menores traços, escondido bem longe de todos os olhares, na poeira dos livros. (Foucault, 2008, p. 28)

Foucault faz, no entanto, a concessão de que não se trata de suspender indefinidamente todo e qualquer tipo de unidade ou rótulo. Em vez disso, propõe que não se parta dessas classificações preconcebidas, e que se deixe o próprio objeto de estudo, através da sua elaboração e crítica, revelar os limiares e recortes que lhe sejam pertinentes. Ao insistir na complexidade e singularidade extremas da emergência histórica de um livro, ou de uma obra, ou de uma ciência, Foucault adverte que noções como influência e evolução são facilmente desfeitas ao se identificarem, como que "de baixo para cima", as regras que as constroem e aquilo que as justifica discursivamente.

Em resumo, mesmo que se parta de rótulos e unidades convencionais para o início do estudo, mesmo que a princípio se organizem os documentos estudados da forma que eles são tradicionalmente apresentados, a tarefa fundamental da arqueologia ao se separar com unidades deve ser questionar:

Que unidades formam; com que direito podem reivindicar um domínio que as especifique no espaço e uma continuidade que as individualize no tempo; segundo que leis elas se formam; sobre o pano de fundo de que acontecimentos discursivos elas se recortam; e se, finalmente, não são, em sua individualidade aceita e quase institucional, o efeito de superfície de unidades mais consistentes (Foucault, 2008, p. 29).

\section{Definições e conceitos}

Como o que se propôs até agora foi a forma de olhar - e, talvez mais importante, o modo como não olhar - para o objeto de estudo dessa arqueologia, cabe a definição do que é exatamente isso que se estuda. Foucault adota o termo território arqueológico para se referir aos recortes sobre os quais se debruça. Mas, para que se compreenda o significado dado a esse termo pelo autor, se faz necessário esclarecer antes os dois conceitos que o caracterizam: a função enunciativa e a formação discursiva (Baptista, 2016).

O enunciado é, de fato, o componente básico da arqueologia, o fragmento menor a partir do qual se constroem as relações e regras que regem determinado território arqueológico. Ainda assim, não pode ser descrito conforme uma estrutura, na mesma medida em que não se pode esperar que todo enunciado se apresente sob a mesma forma: "é que ele não é em si mesmo uma unidade, mas sim uma função que cruza um domínio de estruturas e de unidades possíveis e que faz com que apareçam, com conteúdos concretos, no tempo e no espaço" (Foucault, 2008, p. 98). Acrescenta ainda que o enunciado é:

Demasiado repetível para ser inteiramente solidário com as coordenadas espaço-temporais de seu nascimento [...], demasiado ligado ao que o envolve e o suporta para ser tão livre quanto uma pura forma [...], ele é dotado de uma certa lentidão modificável, de um peso relativo ao campo em que está colocado, de uma constância que permite utilizações diversas, de uma permanência temporal que não tem a inércia de um simples traço, e que não dorme sobre seu próprio passado (Foucault, 2008, p. 98). 
Os enunciados são, portanto, o componente fundamental das formações discursivas, sendo o discurso, por sua vez, "um conjunto sequencial e enunciativo de signos" (Baptista, 2016, p. 282). Essa organização de enunciados em formações discursivas se dá através da identificação de regras de formação. Visto que os enunciados podem ter as mais diferentes formas e estruturas (inclusive para além do espectro verbal), pode-se afirmar que é justamente nessa dispersão que se observam as regras que permitem organizar enunciados em formações discursivas. Para tanto, se faz necessário "descrever um conjunto de enunciados [...] como figura lacunar e retalhada; [não pela interioridade da sua origem, mas] segundo a dispersão de uma exterioridade; descrever um conjunto de enunciados para aí reencontrar [...] as formas específicas de um acúmulo" (Foucault, 2008, p. 141).

Na base teórica do Design da Informação, são identificáveis vários pontos de partida enunciativo-discursivos. Pettersson (2014) menciona sete "teorias do design da informação" que, evidenciando a transversalidade epistemológica da disciplina, advém de campos de conhecimento cujas contribuições facilitam o cultivo do olhar arqueológico do campo. Outros exemplos comuns incluem a escala de eficácia e eficiência em sinais de advertência de Wogalter (1999), em cujo ápice está o objetivo de conseguir influenciar comportamentos por meio da informação comunicada de maneira otimizada; e a teoria cognitiva de aprendizagem multimídia de Mayer (1997), que providencia embasamento para que artefatos cuja principal característica seja a combinação de elementos heterogêneos em apreensão cognitiva (e.g. sons e imagens) possam ser estudados pelo Design da Informação.

Um conjunto de formações discursivas identificadas em determinado recorte de espaçotempo delimita-se, arqueologicamente, como uma episteme: "um espaço inesgotável [que] não pretende englobar todos os conhecimentos de um espaço-tempo, pois convive com outras epistemes" (Baptista, 2016, p. 283). É um espaço de possibilidades que, ao mesmo tempo, regula e permite o surgimento de novas formações discursivas. Os limiares desse espaço são pressões que conformam o aparecimento e a manutenção de determinados tipos de enunciado que, por sua vez, se revelam na forma de convenções, censuras, coações e limites instaurados em determinada época (Foucault, 2008).

Por fim, as relações identificadas entre diferentes epistemes - os vetores enunciativos que conectam, através daqueles estratos separados por rupturas, diferentes formações discursivas - são denominadas por Foucault como feixes de relações. Tais conexões são o que permite a continuidade de enunciações, conceitos e estratégias ao longo da história. Não que estes sejam anteriores ao discurso per se. Pelo contrário, é o fluxo desses feixes de relações que, ao passarem de uma episteme para outra, conservam antigas regras de formação em novos discursos. Enunciações, conceitos e estratégias são, portanto, consequências do discurso, tanto que estes podem surgir também em novas formas independente das continuidades e dos feixes de relações - sem que haja uma conexão intrínseca com formas anteriores (Figura 1). 
Figura 2: Visualização do Método Arqueológico. (Fonte: Os autores)

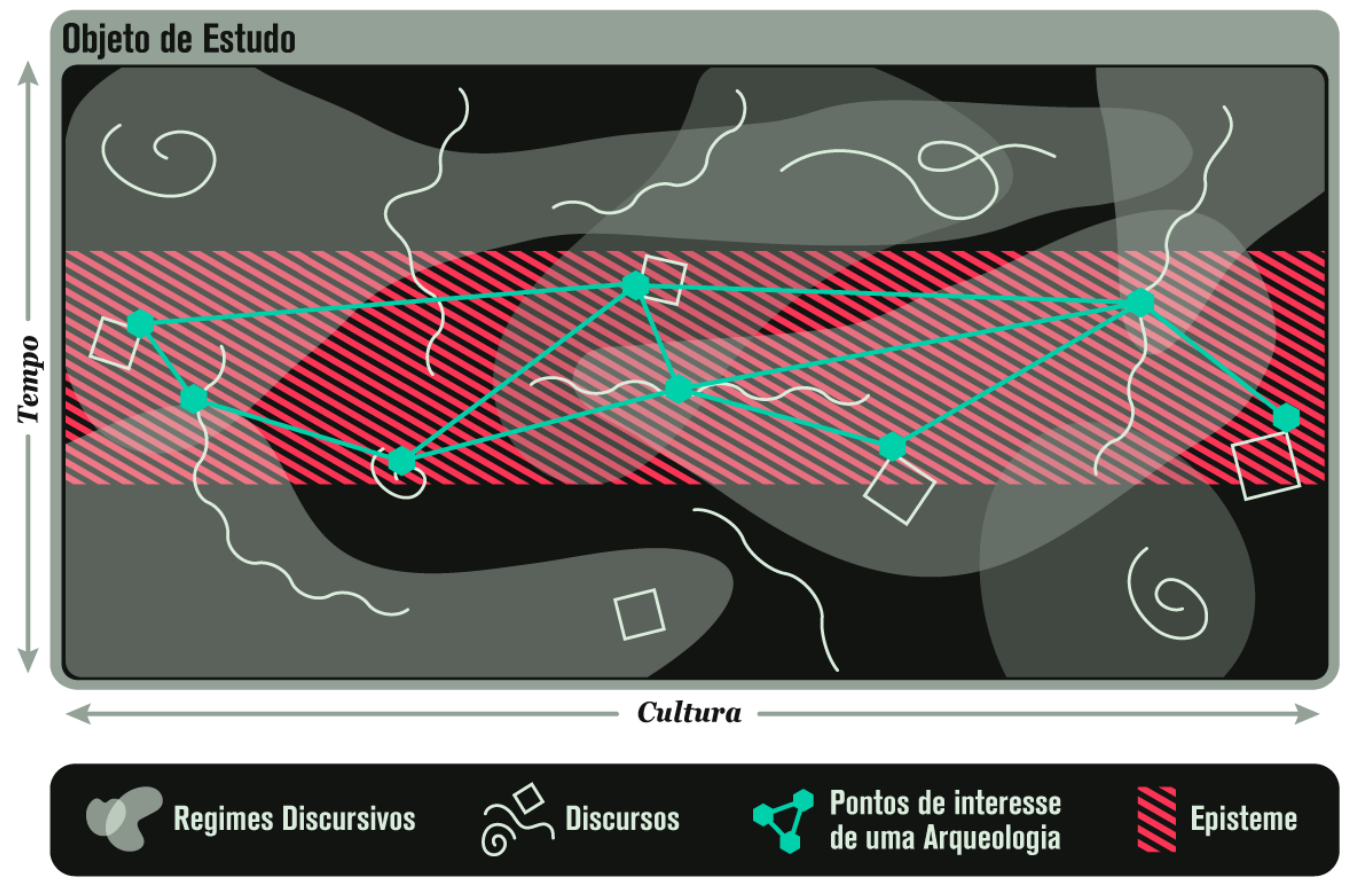

O que pode ser dito sobre as diferentes epistemes do Design da Informação é justamente a prevalência daquilo que Beccari (2020) caracteriza como um "modo de olhar" (p. 214). O modo de olhar do Design da Informação parte de uma disposição histórica que permite identificar um alinhamento discursivo que une os gráficos de Playfair, os diagramas de Nightingale e o mapa do metrô de Londres de Beck. Na seção seguinte, esboçamos uma proposta de ampliação desse olhar por meio do método arqueológico foucaultiano.

\section{Uma arqueologia do Design da Informação}

Apesar de ter como objeto original "essas disciplinas tão incertas de suas fronteiras, tão indecisas em seu conteúdo, que se chamam história das idéias, ou do pensamento, ou das ciências ou dos conhecimentos" (Foucault, 2008, p. 23), a arqueologia se expande para além da obra de Foucault para abarcar horizontes diversos. Como pontuamos de início, a aproximação do pós-estruturalismo com o design gráfico em Cranbrook demonstra o potencial e o desenvolvimento de novas ideias que se encontram nessa intersecção inesperada. Ao aplicar o método arqueológico na pesquisa em design, acredita-se que "as limitações da arqueologia só a fortalece, tornando-a um modelo possível de entendimento da realidade, sem propostas herméticas, sem pretensões à irrefutabilidade" (Baptista, 2016, p. 284).

Trata-se, portanto, de deslocar o enfoque arqueológico para novos horizontes; para além da formação epistêmico-discursiva da psicologia e das ciência humanas; para outros registros que não se limitem ao documento escrito e à fonte historiográfica; para a história do design; para as dinâmicas da moda no século $X X$, as taxonomias dos jogos digitais, a infografia digital, a tipografia holandesa do século XXI; para cartazes, peças de vídeo, artefatos de interface, 
padrões de superfície; enfim, para todo objeto de estudo que se proponha investigar com novos olhos, não como documento empoeirado que pretende corroborar com as narrativas estabelecidas, mas sim como monumento que contém nele próprio enunciados e vestígios de um regime discursivo particular.

Se os enunciados de Mijksenaar, por exemplo, permitem-nos encontrar uma "receita" propedêutica do Design da Informação, é porque o nosso modo de olhar aceita que certos "ingredientes" possam servir como critério. É também possível argumentar, tomando de empréstimo os termos de Hacking (1992), que estamos criando uma pessoa ("making up people"), um designer da informação, que em seu repertório visual é capaz de, primeiramente, acreditar nessa receita. Como poderia alguém, deslocado desse discurso do que é eficaz e agradável visualmente, propor uma interpretação sobre aquilo que se considera "legível" ou "ilegível"?

O método arqueológico mostra-se como um caminho profícuo para o estudo da formação discursiva do Design da Informação enquanto um agregado de epistemes que, derivadas de diversos outros campos, permitem a designers olhar para o jornalismo, por exemplo, e ver na infografia - com sua organização de palavras, ilustrações e formas esquemáticas - um potencial objeto de interesse; mas também olhar para a cartografia e identificar, nas estratégias que mapas usam para delimitar territórios significativos por meio da saturação das cores, uma manifestação da busca pela eficácia comunicacional. É o olhar que permite o entendimento de algo feito em épocas longínquas, nas quais ainda não exista corpo discursivo para pensar em termos de "design da informação", como algo feito por alguém que atua, avant la lettre, como um designer da informação.

O desafio que resta é permitir que esse modo de olhar desloque-se para onde ele ainda não repousa, por meio de novas intenções de olhar. Beccari (2020) elabora: "A visualidade condiciona os discursos" (p. 215). Se há no Design da Informação a premissa de poder ver esse tipo específico de design lá onde ele não existia originalmente, consideremos também a possibilidade de estarmos, também, onde ainda não estamos vendo. Eis o potencial arqueológico: a abertura para ver/ser outra coisa.

\section{Referências}

Baptista, I. F. (2016) A Arqueologia do Saber de Michel Foucault no campo da Comunicação. Linguagens - Revista de Letras, Artes e Comunicação, v. 10, n. 2, 275-287.

Beccari, M. N., Portugal, D. B., \& Padovani, S. (2017) Seis eixos para uma filosofia do design. Estudos em Design, v. 25, n. 1., 13-32.

Beccari, M. N. (2020) Das coisas ao redor: discurso e visualidade a partir de Foucault. São Paulo: Edições 70.

Bomeny, M. H. W. (2009) O Panorama do design gráfico contemporâneo: a construção, a desconstrução e a nova ordem. [Tese de doutorado, Universidade de São Paulo]. São Paulo: FAUUSP. 
Camargo, I. P. (2011) O Departamento de Design Gráfico da Cranbrook Academy of Art (19711995): novos caminhos para o design. [Dissertação de mestrado, Universidade de São Paulo]. São Paulo: FAUUSP.

Castro, E. (2011) Introdução a Foucault. Belo Horizonte: Autêntica.

Chromiec, E. L. E. (2020) Formalismo e design gráfico: uma análise crítica sobre as teorias contemporâneas de percepção visual, sob o viés pós-estruturalista. [Dissertação de mestrado, Universidade Federal do Paraná]. Curitiba: PPGDesign UFPR.

Costa, F. Z. N., Guerra, J. R. F., \& Leão, A. M. S. (2013) O Solo Epistemológico de Michel Foucault: Possibilidades de Pesquisa no Campo da Administração. Revista de Ciências da Administração: RCA, v. 15, n. 35, 168-179.

Foucault, M. (2005) Estruturalismo e pós-estruturalismo. In: Ditos e Escritos II: Arqueologia das Ciências e História dos Sistemas de Pensamento. Rio de Janeiro: Forense Universitária, p. 307-334.

Foucault, M. (2008) A Arqueologia do Saber. Rio de Janeiro: Forense Universitária.

Gomes, R. M. (2018) A Arqueologia do Saber: uma proposta metodológica para a análise do discurso em História. Interfaces Científicas - Humanas e Sociais, v. 6, n. 3, 19-26.

Hacking, I. (1992) Making up people. In: Stein, E. (Org.). Forms of Desire. New York: Routledge, 1992, pp.

Lupton, E., \& Miller, A. (2011) Design escrita pesquisa: a escrita no design gráfico. Porto Alegre: Bookman.

Martins, F. D. O., Lima, E. L. C., \& Lima, G. C. (2015). Análise de duas propostas metodológicas para a pesquisa em História do Design Gráfico. In: C. G. Spinillo; L. M. Fadel; V. T. Souto; T. B. P. Silva \& R. J. Camara (Eds). Anais do $7^{\circ}$ Congresso Internacional de Design da Informação/Proceedings of the 7th Information Design International Conference | CIDI 2015, 2(2), 938-947.

Mayer, R. E. (1997) Multimedia Learning: Are We Asking the Right Questions? Educational Psychologist, v. 32, n. 1, 1-19.

Mijksenaar, P. (1997) Visual function: an introduction to information design - Vol. 1. Rotterdam: 010 Publishers.

Neves, I., \& Santos, V. S. (2014) A "fala errada" dos indígenas nas telenolevas brasileiras: entre o saber e o poder. Revista Comunicação Midiática, v. 9, n. 3, 69-85.

Pettersson, R. (2010) It depends. Wien: International Institute for Information Design.

Pettersson, R. (2014) Information design theories. Journal of Visual Literacy, v. 33, n. 1, 1-96.

Pires, F. S., \& Botazzo, C. (2015) Organização tecnológica do trabalho em saúde bucal no SUS: uma arqueologia da política nacional de saúde bucal. Saúde e Sociedade, v. 24, n. 1, 273-284.

Schriver, K. A. (1997) Dynamics in document design: Creating texts for readers. New York, NY: John Wiley \& Sons.

Tufte, E. R. (1990) Envisioning information. Cheshire, CT: Graphics Press.

Twyman, M. (1982). The graphic presentation of language. Information design journal, v. 3, n. 1 , p. 2-22. 
Wogalter, M. (1999) Factors influencing the effectiveness of warnings. In Zwaga, H., Boersema, T., \& Hoonhout, H. (Eds.). Visual information for everyday use: Design and research perspectives (pp. 93-109). London: Taylor \& Francis.

\section{Sobre os autores}

Mauricio Perin, Me., UFPR, Brasil mauricio.perin@gmail.com

Bolívar Escobar, Me., UFPR, Brasil bolivarescobar@gmail.com

Marcos Beccari, Dr., UFPR, Brasil contato@marcosbeccari.com 